\title{
Presence of Thyroid-Stimulating Hormone Receptor Antibodies in a Patient with Subacute Thyroiditis followed by Hypothyroidism and Later Graves' Disease with Ophthalmopathy: A Case Report
}

\author{
Bengt Hallengren ${ }^{a, c}$ Tereza Planck ${ }^{a, c}$ Peter Åsman ${ }^{b, c}$ Mikael Lantz ${ }^{a, c}$ \\ Departments of ${ }^{\mathrm{a} E}$ Endocrinology and ${ }^{\mathrm{b}}$ Ophthalmology, Skåne University Hospital, Malmö, and ${ }^{\mathrm{c}}$ Department of Clinical \\ Sciences, Lund University, Lund, Sweden
}

\section{What Is Known About This Topic?}

- Subacute thyroiditis (SAT) is, in most cases, a self-limiting, rather uncommon inflammatory disorder usually followed by a recovery of normal thyroid function. The development of Graves' disease (GD) after SAT is very rare and only a limited number of cases of GD occurring after SAT have been reported.

\section{What Does This Case Report Add?}

- It adds to the limited number of cases of GD occurring after SAT. It also illustrates the appearance of thyroid-stimulating hormone receptor antibodies 1 year after SAT, the development of hypothyroidism requiring thyroxine and the occurrence of GD with severe ophthalmopathy 11 years after SAT.

\section{Key Words}

Subacute thyroiditis - Graves' disease - Endocrine ophthalmopathy · Thyroid-stimulating hormone receptor antibody

\section{Abstract \\ Background: The development of Graves' disease (GD) af- ter subacute thyroiditis (SAT) is very rare and only a limited number of cases have been reported. Objectives: Here, we report a patient with SAT followed by hypothyroidism and}

later GD, with ophthalmopathy, occurring 11 years after SAT. Conclusion: This case illustrates the appearance of thyroid-stimulating hormone (TSH) receptor antibodies in a female 1 year after SAT, the development of hypothyroidism requiring thyroxine, and later the occurrence of GD with severe ophthalmopathy, 11 years after SAT. The occurrence of SAT and GD may be coincidental but SAT may have

Presented in part at the 38th Annual Meeting of the European Thyroid Association in Santiago de Compostela, Spain, 2014.

$\begin{array}{ll}\text { KARGER 125/s } & \begin{array}{l}\odot 2015 \text { European Thyroid Association } \\ \text { Published by S. Karger AG, Basel } \\ \text { 2235-0640/15/0043-0197\$39.50/0 }\end{array} \\ \begin{array}{l}\text { E-Mail karger@karger.com } \\ \text { www.karger.com/etj }\end{array} & \end{array}$

Bengt Hallengren, $\mathrm{MD}, \mathrm{PhD}$

Department of Endocrinology

Skåne University Hospital

SE-20502 Malmö (Sweden)

E-Mail bengt.hallengren@med.lu.se 
induced the appearance of TSH-receptor antibodies, with the bioactivity changing from blocking, leading to hypothyroidism, and later to a stimulating activity that led to GD in a genetically susceptible patient.

(C) 2015 European Thyroid Association Published by S. Karger AG, Basel

\section{Introduction}

Subacute thyroiditis (SAT) is, in most cases, a self-limiting, possibly viral, inflammatory disorder usually followed by a recovery of normal thyroid function [1]. The development of Graves' disease (GD) after SAT is very rare, and only a limited number of cases of GD occurring after SAT have been reported [2-6]. Here, we report a case of GD with opthalmopathy occurring 11 years after SAT with thyroid-stimulating hormone (TSH) receptor antibodies present and hypothyroidism requiring thyroxine.

\section{Material and Methods}

\section{Assays}

In 1999-2000, TSH receptor antibodies were measured by a second-generation radioreceptor assay [TRAK-assay, Henning, Berlin, Germany; reference range $<10$ arbitrary units (arbU)]. In 2004, TSH receptor antibodies were measured using a human radioreceptor assay (B.R.A.H.M.S.; reference range $<1 \mathrm{U} / 1$, sensitivity 0.3 IU/l, contingent valuation 9.3-15.4\%) kit. In 1999, antithyroperoxidase antibodies (anti-TPOabs) were analyzed by a chemiluminescence enzyme immunological method (cobas, Roche Diagnostics Ltd., Burgess Hill, West Sussex, UK; reference range 0-70 U/ $\mathrm{ml}$ ). In 2010, anti-TPO titer was measured with a sandwich ELISA technique (Diagnostic Products Corp.; reference range $<35$ kIU/l).

The described assays were all performed according to manufacturers' instructions in a routine clinical laboratory at the Department of Clinical Chemistry in Malmö.

\section{HLA-DR Typing}

DNA was extracted from the patient's peripheral blood. PCR was done using low-and high-resolution Olerup PCR-SSP HLAtyping kits $[7,8]$.

Ethics

The patient was fully informed and has given her consent for this case report.

\section{Case Report}

A 43-year-old, nonsmoking female, whose grandmother had thyrotoxicosis, developed SAT in March 1998. The diagnosis was verified by fine-needle aspiration with cytological examination (fig. 1). She was given glucocorticoids and needed these for 1 year. In September 1998, her serum TSH level was elevated to $41 \mathrm{mIU} / \mathrm{l}$ (ref-

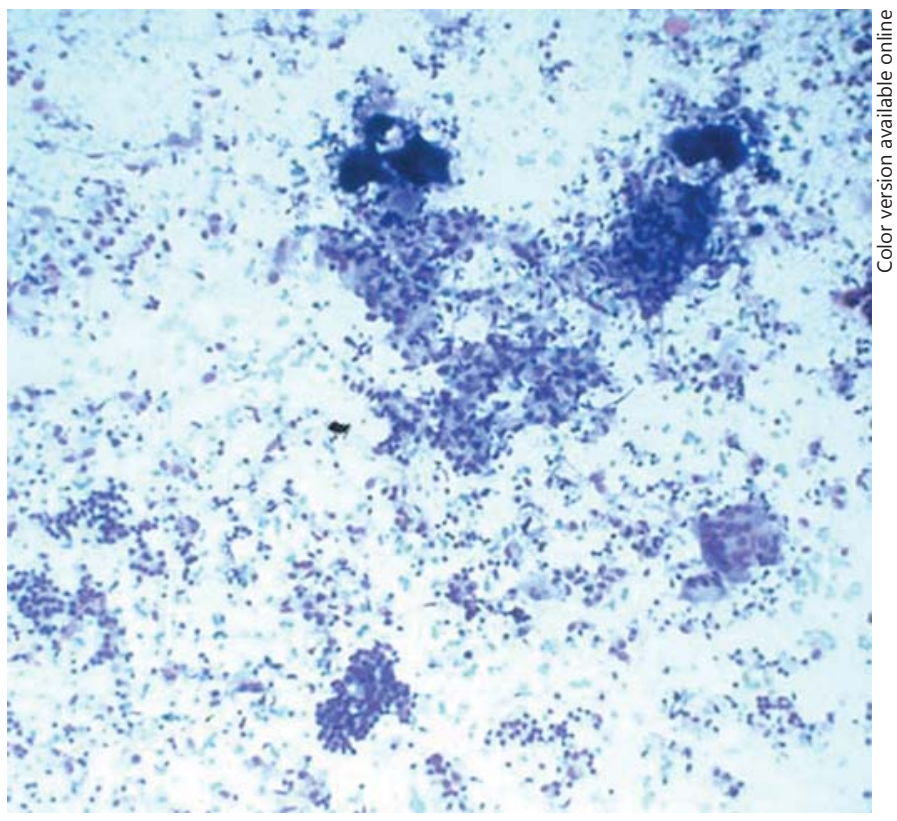

Fig. 1. Fine-needle aspiration of the thyroid gland shows cytological features consistent with SAT.

erence range 0.4-4.0) and decreased without thyroxine treatment, but biochemical subclinical hypothyroidism remained into 1999. She was found to be negative for TPOabs. In May 1999, serum TSH receptor antibodies ( 35 arbU; reference range $<10$ ) were detected; these decreased during the autumn, and 11 arbU were measured in December 1999. The patient was then admitted to the Department of Endocrinology. She had biochemical subclinical hypothyroidism and hypothyroid symptoms, so thyroxine substitution was instituted. In March 2000, she was feeling well; TSH was $0.89 \mathrm{mIU} / \mathrm{l}$ and TSH receptor antibodies had normalized (7 arbU). In 2004-2008, she felt healthy on thyroxine substitution. TSH receptor antibody concentration (TRAK) levels were then measured with a more sensitive method than before and were found to be elevated (2-2.6 IU/l; reference range $<1$ ). In January 2010, she appeared with a history of hyperthyroid symptoms that she had had for 1 month. On physical examination she was sweating, had tremor and also signs of endocrine ophthalmopathy. TRAK was $28 \mathrm{IU} / \mathrm{l}$, TSH was $<0.02 \mathrm{mIU} / \mathrm{l}$, GD with ophthalmopathy was diagnosed and methimazole instituted. HLA-typing demonstrated HLA-B*35 and HLA-DRB1*03. Over the next few months, the patient developed serious ophthalmopathy with periorbital swelling, redness of the conjunctiva, conjunctival edema, impaired eye motility with diplopia and increasing exophthalmos, i.e. from $20 / 18 \mathrm{~mm}$ (right eye/left eye) in January to $25 / 24$ $\mathrm{mm}$ in April and 26/27 mm in June 2010. TPOab levels were undetectable (table 1). She received corticosteroid infusions (metylprednisolon total dose $6 \mathrm{~g}$ ) in May and experienced a temporary improvement. In June 2010, impairment of visual fields and visual acuity developed and orbital decompression was performed. Following decompression, the signs of optical dysfunction disappeared. The thyrotoxicosis was treated with methimazole and thyroxine in block and replace dosages. The TRAK titer remained elevated and a total thyroidectomy was performed in June 2011. 
Table 1. Levels of TSH receptor antibody (TRAb and TRAK) and anti-TPOab in a female patient with SAT, the development of hypothyroidism and later the occurrence of GD with ophthalmopathy

\begin{tabular}{llllllr}
\hline & $\begin{array}{l}\text { March 1998 } \\
\text { SAT }\end{array}$ & $\begin{array}{l}\text { September 1998 } \\
\text { HT }\end{array}$ & May 1999-March 2000 & 2004-2008 & January 2010 \\
GD & April 2010 \\
\hline TRAb, arbU $(<10)$ & & 35 & 11 & 7 & & 18 \\
TRAK, IU $(<1)$ & & & $22 \mathrm{U} / \mathrm{ml}$ & $2.0-2.6$ & 28 & $<10 \mathrm{kU} / 1$ \\
TPOab $^{\mathrm{a}}$ & & & & \\
\hline
\end{tabular}

HT = Hypothyroidism.

a 1999 reference range $0-70,2010$ reference range $<35$.

\section{Discussion}

The appearance of TSH receptor antibodies and the occurrence of GD have been described following radioactive iodine treatment for toxic nodular goiter [9]. A similar mechanism may explain the development of GD following SAT. SAT is characterized by thyroid destructive phenomena, and thyroid damage may cause the release or expression of antigens, that leads to antibody production. In about $2 \%$ of patients, SAT may trigger autoreactive B cells to produce TSH receptor antibodies, resulting in TSH receptor antibody-associated thyroid dysfunction in some patients [10]. Thyroid function after the development of TSH receptor antibodies appears to be influenced by the bioactivity of antibodies including stimulating antibodies, blocking antibodies and apparently nonfunctioning antibodies [10]. Iitaka et al. [11] described a patient who sequentially developed hypothyroidism positive for TSH receptor blocking antibodies, followed by hyperthyroidism positive for TSH receptorstimulating antibodies, after an episode of SAT. This was similar to our patient who developed TSH receptor antibodies and hypothyroidism, which remained for over 1 year and required treatment with thyroxine; later, she developed GD with ophthalmopathy. We could not measure the bioactivity of the TSH receptor antibodies, but as our patient was TPOAb-negative, one might speculate that she initially had TSH receptor-blocking antibodies leading to sustained hypothyroidism, and that the antibodies later changed to stimulating antibodies. No measurements of TSH receptor antibodies were present before or at the diagnosis of SAT. TSH receptor antibodies were detected 1 year after this diagnosis and the decrease after detection indicated that the antibodies were induced by the SAT.

Without genetic susceptibility, a SAT-induced autoimmune reaction is only transient $[4,12]$. It has been sug- gested that genetic susceptibility exists in patients who develop SAT followed by GD [4]. HLA-typing in our patient demonstrated a genetic predilection for SAT (HLA$\left.B^{*} 35\right)$ and GD (HLA-DRB1*03) in agreement with previous reports $[4,5,13]$.

SAT is a rather uncommon inflammatory disorder of the thyroid and only a few incidence studies are available. Of 160 patients studied in the period 1960-1997 at the Mayo Clinic, an age- and sex-adjusted incidence of 4.9 cases of SAT/100,000/year was noted [1]. Early transient hypothyroidism is common in SAT but permanent hypothyroidism is less common [1]. The occurrence of GD after SAT is very rare. In a report from Japan [6], 7 patients with SAT followed by GD were encountered during a period of 24 years at a thyroid clinic; these 7 comprised $0.15 \%$ of the 4,617 patients with GD and $0.76 \%$ of the 918 patients with SAT. In this particular study, the intervals between the onsets of SAT and GD were 1-8 months. In the literature, intervals between simultaneous occurrence and an interval of up to 8 years have been described [4-6]. In our patient, it was a very long interval, of 11 years, between the SAT and the occurrence of GD. This could have been coincidental, but TSH receptor antibodies were elevated for up to 21 months following the diagnosis of SAT and, upon testing with a more sensitive method, they reappeared 6 years before the diagnosis of GD. It has been reported that multiple thyroid antibodies may persist for 39 months after the occurrence of SAT [14].

Our patient had endocrine ophthalmopathy which deteriorated rapidly. She had high TRAK levels and low or undetectable levels of TPOAbs. This is in agreement with our previous study [15], i.e. that this combination predisposes to endocrine ophthalmopathy [16]. The incidence of GD ophthalmopathy in patients with previous SAT is unknown but some cases have been described [6]. 
This case illustrates the appearance of TSH receptor antibodies in a female 1 year after SAT, the development of hypothyroidism requiring thyroxine, and the occurrence of GD with severe ophthalmopathy 11 years after SAT. The occurrence of SAT and GD may be coincidental but SAT may have induced the appearance of TSH receptor antibodies, with the bioactivity changing from blocking, leading to hypothyroidism, to a stimulating activity which led to GD in a genetically susceptible patient.

\section{Acknowledgements}

Dr. Ann-Sofie Liedberg is gratefully acknowledged for performing the HLA-analyses. This work was supported by grants from the research funds of Malmö University Hospital, the Faculty of Medicine at Lund University and the Skåne Research Foundation.

\section{Disclosure Statement}

The authors have no conflicts of interest to disclose.

\section{References}

1 Fatourechi V, Aniszevski JP, Fatourechi GZE, Atkinson EJ, Jacobsen SJ: Clinical features and outcome of subacute thyroiditis in an incidence cohort: Olmsted County, Minn. Study. J Clin Endocrinol Metab 2003;88: 2100-2105.

2 Perloff WH: Thyrotoxicosis following acute thyroiditis. A report of 5 cases. J Clin Endocrinol Metab 1956;16:542-546.

-3 Werner SC: Graves' disease following acute (subacute) thyroiditis. Arch Intern Med 1979; 139:1313-1315.

4 Bartalena L, Bogazzi F, Pecori F, Martino E: Graves' disease occurring after subacute thyroiditis: report of a case and review of the literature. Thyroid 1996;6:345-348.

5 Hoang TD, Mai VQ, Clyde PW, Shakir KM: Simultaneous occurrence of subacute thyroiditis and Graves' disease. Thyroid 2011;21: 1397-1400.

6 Nakano Y, Kurihara H, Sasaki J: Graves' disease following subacute thyroiditis. Tohoku J Exp Med 2011;225:301-309.

7 Olerup O, Zetterquist H: HLA-DRB1*01 subtyping by allele-specific PCR amplification: a sensitive, specific and rapid technique. Tissue Antigens 1991;37:197-204.

8 Olerup O, Zetterquist H: HLA-DR typing by PCR amplification with sequence-specific primers (PCR-SSP) in 2 hours: an alternative to serological DR typing in clinical practice including donor-recipient matching in cadaveric transplantation. Tissue Antigens 1992;39:225-235.

-9 Nygaard B, Faber J, Veje A, Hegedus L, Hansen JM: Appearance of Graves'-like disease after radioiodine therapy for toxic as well as non-toxic multinodular goitre. Clin Endocrinol (Oxf) 1995;43:129-130.

10 Iitaka M, Momotani N, Hisaoka T, Noh JY, Ishikawa N, Ishii J, Katayama S, Ito K: TSH receptor antibody-associated thyroid dysfunction following subacute thyroiditis. Clin Endocrinol (Oxf) 1998;48:445-453.

11 Iitaka M, Kakinuma S, Yamanaka K, Fujimaki S, Oosuga I, Wada S, Katayama S: Induction of autoimmune hypothyroidism and subsequent hyperthyroidism by TSH receptor antibodies following subacute thyroiditis: a case report. Endocrine J 2001;48:139-142.
2 Strakosch CR, Joyner D, Wall JR: Thyroid stimulating antibodies in patients with subacute thyroiditis. J Clin Endocrinol Metab 1978;46:345-348.

13 Wartofsky L, Schaaf M: Graves' disease with thyrotoxicosis following subacute thyroiditis. Am J Med 1987;83:761-763.

14 Weetman AP, Smallridge RC, Nutman TB, Burman KD: Persistent thyroid autoimmunity after subacute thyroiditis. J Clin Lab Immunol 1987;23:1-6.

15 Lantz M, Planck T, Åsman P, Hallengren B: Increased TRAb and/or low anti-TPO titers at diagnosis of Graves' disease are associated with an increased risk of developing ophthalmopathy after onset. Exp Clin Endocrinol Diabetes 2014;122:113-117.

16 Khoo DH, Ho SC, Seah LL, Fong KS, Tai ES, Chee SP, Eng PH, Aw SE, Fok AC: The combination of absent thyroid peroxidase antibodies and high thyroid-stimulating immunoglobulin levels in Graves' disease identifies a group at markedly increased risk of ophthalmopathy. Thyroid 1999;9:11751180. 